\title{
Renoprotective Effects of a Novel Receptor-Interacting Protein Kinase 2 Inhibitor, AS3334034, in Uninephrectomized Adriamycin-Induced Chronic Kidney Disease Rats ${ }^{[}$
}

\author{
Yusuke Wada, Mitsuhiro Kondo, Kumi Sakairi, Akira Nagashima, (D Kenichi Tokita, \\ Hiroaki Tominaga, Hiroshi Tomiyama, and Tomohisa Ishikawa \\ Drug Discovery Research, Astellas Pharma Inc., Ibaraki, Japan (Y.W., M.K., K.S., A.N., K.T., H.T.); Research and Development \\ Department, Kotobuki Pharmaceutical Co., Ltd., Nagano, Japan (H.T.); and Department of Pharmacology, School of \\ Pharmaceutical Sciences, University of Shizuoka, Shizuoka, Japan (Y.W., T.I.)
}

Received February 18, 2020; accepted June 12, 2020

\begin{abstract}
Renal inflammation is a final common pathway of chronic kidney disease (CKD), and its progression can be used to effectively gauge the degree of renal dysfunction. Inflammatory mechanisms contribute to glomerulosclerosis and tubulointerstitial fibrosis, which are hallmarks of CKD leading to end-stage renal disease. Receptor-interacting protein kinase 2 (RIP2) is largely committed to nucleotide-binding oligomerization domain signaling as a direct effector and transmits nuclear factor $-\kappa \mathrm{B}$ $(\mathrm{NF}-\kappa \mathrm{B})-$ mediated proinflammatory cytokine production. In the present study, we hypothesized that if inflammation via RIP2 and $\mathrm{NF}-\kappa \mathrm{B}$ signaling plays an important role in renal failure, then the anti-inflammatory effect of RIP2 inhibitors should be effective in improving CKD. To determine its pharmacologic potency, we investigated the renoprotective properties of the novel RIP2 inhibitor AS3334034 [7-methoxy-6-(2-methylpropane2-sulfonyl)- $N$-(4-methyl-1H-pyrazol-3-yl)quinolin-4-amine] in uninephrectomized adriamycin-induced CKD rats. Six weeks' repeated administration of AS3334034 (10 mg/kg, once daily) significantly reduced urinary protein excretion and prevented the development
\end{abstract}

of glomerulosclerosis and tubulointerstitial fibrosis. In addition, AS3334034 showed beneficial effects on renal function, as demonstrated by a decrease in levels of plasma creatinine and blood urea nitrogen and attenuation of a decline in creatinine clearance. Furthermore, AS3334034 significantly attenuated inflammation, renal apoptosis, and glomerular podocyte loss. These results suggest that the RIP2 inhibitor AS3334034 suppresses the progression of chronic renal failure via an anti-inflammatory effect and is therefore potentially useful in treating patients with CKD.

\section{SIGNIFICANCE STATEMENT}

The receptor-interacting protein kinase 2 (RIP2) inhibitor AS3334034 suppresses the progression of chronic renal failure via an antiinflammatory effect, suggesting that the nucleotide-binding oligomerization domain-RIP2 axis might play a crucial role in the pathogenesis of inflammatory kidney diseases. AS3334034 is expected to be potentially useful in the treatment of patients with chronic kidney disease.

\section{Introduction}

Chronic kidney disease (CKD) is defined by structural kidney damage, such as glomerulosclerosis and interstitial fibrosis, and a sustained decline in renal function as determined by a decreased glomerular filtration rate. It is estimated that over $10 \%$ of the population worldwide is affected by CKD (López-Novoa et al., 2010). CKD progresses under the influence of various etiological factors, such as diabetes, hypertension, obesity, aging and nephrotoxic exposures,

Y.W., M.K., K.S., A.N., K.T., and H.T. are employees of Astellas Pharma Inc. The study was funded by Astellas Pharma Inc.

https://doi.org/10.1124/jpet.120.265678.

S This article has supplemental material available at jpet.aspetjournals.org. and along with nephritis, nephrotic syndrome, and acute kidney injury (Kazancioğlu, 2011; Sharma et al., 2018). Moreover, CKD imposes a substantial burden on patients owing to irreversible progressive deterioration of renal function, which ultimately leads to end stage renal disease (ESRD), together with a high risk of cardiovascular disease and all-cause mortality. Despite the success of treatment with several drugs, including angiotensin-converting enzyme (ACE) inhibitors and angiotensin II receptor blockers (ARBs), the absolute risk of renal and cardiovascular morbidity and mortality in patients with CKD remains devastatingly high (Lambers Heerspink and de Zeeuw, 2013), and novel drugs that effectively halt the progression of renal function loss are thus strongly desired.

ABBREVIATIONS: ACE, angiotensin-converting enzyme; ARB, angiotensin II receptor blocker; AS3334034, 7-methoxy-6-(2-methylpropane-2sulfonyl)- $N$-(4-methyl-1H-pyrazol-3-yl)quinolin-4-amine; BUN, blood urea nitrogen; CARD, caspase activation and recruitment domain; CKD, chronic kidney disease; ESRD, end stage renal disease; IL, interleukin; MCP-1, monocyte chemoattractant protein 1; MDP, muramyl dipeptide; NF$\kappa \mathrm{B}$, nuclear factor $\kappa-\mathrm{B}$; NOD, nucleotide-binding oligomerization domain; Nx, nephrectomized; RIP, receptor-interacting protein kinase; TNF- $\alpha$, tumor necrosis factor $\alpha$; TUNEL, terminal deoxynucleotidyl transferase-mediated digoxigenin-deoxyuridine nick-end labeling; WT-1, Wilms' tumor 1. 
There is firm evidence that CKD and ESRD are both characterized by a chronic low-grade inflammatory state, as evidenced by increased levels of proinflammatory cytokines including interleukin (IL)- $1 \beta$ and monocyte chemoattractant protein 1 (MCP-1) (Silverstein, 2009; Stinghen et al., 2009; Tbahriti et al., 2013). In addition, a persistent inflammatory state may also be a risk factor for progression of CKD and may substantially contribute to morbidity and mortality, possibly resulting in a vicious inflammatory-driven cycle (Suliman and Stenvinkel, 2008). Although a complex array of tightly regulated events involving various proinflammatory cytokines and multiple inflammatory signaling pathways might be related, the causes of dysregulated inflammation in CKD are still not well understood.

Receptor-interacting protein (RIP) kinases act as essential sensors of cellular stress (Meylan and Tschopp, 2005; Zhang et al., 2010). They play important roles in situations of cellular stress caused by various factors, such as pathogen infection, inflammation, and several types of cellular damage, and these eventually lead to the activation of transcription factors such as nuclear factor $-\kappa \mathrm{B}(\mathrm{NF}-\kappa \mathrm{B})$, the induction of apoptotic processes, or activation of mitogen-activated protein kinase (Humphries et al., 2015). Among the RIP kinase family, RIP2 uniquely has a caspase activation and recruitment domain (CARD) and specifically binds to nucleotide-binding oligomerization domain (NOD) proteins NOD1 and NOD2, upstream molecules, via CARD-CARD interaction (Jun et al., 2013). NOD proteins are intracellular pattern recognition receptors that recognize peptidoglycan fragments of bacteria invading into the cell or sense cellular stress such as endoplasmic reticulum stress (Keestra-Gounder et al., 2016) and consequently propel innate immunity and inflammatory responses via RIP2 as a direct effector. Thus, RIP2 plays a central role in the NOD-mediated inflammatory signaling pathway (Saxena and Yeretssian, 2014). Given the critical role of RIP2 in inflammatory processes, the modulation of RIP2 kinase activity might be an attractive therapeutic approach for the treatment of various diseases associated with dysregulated inflammation, including kidney disease (Shigeoka et al., 2010). However, although several RIP2 inhibitors have been identified (Salla et al., 2018), the role of RIP2 in inflammatory diseases such as CKD has not been elucidated. We hypothesized that, if persistent inflammation does indeed play a key role in renal failure, then the anti-inflammatory effect of RIP2 inhibitors might be effective in alleviating CKD.

In the present study, we characterized the pharmacological properties of AS3334034 [7-methoxy-6-(2-methylpropane-2sulfonyl)- $N$-(4-methyl-1H-pyrazol-3-yl)quinolin-4-amine; Fig. 1], a newly synthesized RIP2 inhibitor. Furthermore, to determine the involvement of RIP2 signaling in renal inflammation and discuss its usefulness in treating kidney diseases, we also evaluated the potential efficacy of this agent in the uninephrectomized adriamycin-induced CKD rat model. In addition, we compared the pharmacologic effects of AS3334034 with those of the ARB losartan, an agent used for the clinical treatment of patients with CKD.

\section{Materials and Methods}

Materials. AS3334034, 7-methoxy-6-(2-methylpropane-2-sulfonyl)$N$-(4-methyl-1H-pyrazol-3-yl) quinolin-4-amine, was synthesized at Astellas Pharma Inc. (Ibaraki, Japan). Losartan potassium was

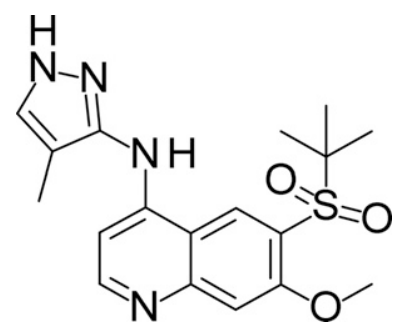

Fig. 1. Chemical structure of AS3334034 (7-methoxy-6-(2-methylpropane2 -sulfonyl)- $N$-(4-methyl-1H-pyrazol-3-yl) quinolin-4-amine).

purchased from LKT Laboratories, Inc. (St. Paul, MN). For in vitro studies, AS3334034 was initially dissolved in dimethyl sulfoxide (DMSO), serially diluted with DMSO, and then diluted to the desired concentration with assay buffer. The final concentration of DMSO in assay buffer did not exceed $0.2 \%$ and was constant throughout the dilution. For in vivo studies, AS3334034 and losartan were suspended or dissolved in 0.5\% methylcellulose solution for oral administration via a stomach tube.

Animals. Male 6-week-old Wistar rats were purchased from Japan SLC, Inc. (Shizuoka, Japan). CKD model rats were prepared as described below. Under isoflurane anesthesia, the left kidney was nephrectomized $(\mathrm{Nx})$. One week later, $5 \mathrm{mg} / \mathrm{kg}$ of adriamycin (Kyowa Hakko Kirin; Tokyo, Japan) dissolved in saline was intravenously administered from the tail vein. Repeated oral administration of drugs was initiated the same day. All animals were housed in groups with a controlled temperature, humidity, 12:12 hours light-dark cycle, and free access to a standard commercial diet and water. All animal experimental procedures were approved by the Institutional Animal Care and Use Committee of Astellas Pharma Inc., Tsukuba Research Center, which is accredited by the Association for Assessment and Accreditation of Laboratory Animal Care International.

RIP2 Kinase Assay. RIP2 kinase assays were performed in assay buffer (50 mM HEPES, pH 7.5, $150 \mathrm{mM} \mathrm{NaCl}, 10 \mathrm{mM} \mathrm{MgCl}_{2}$, $0.05 \%$ Tween-20, $1 \mathrm{mM}$ dithiothreitol, and $0.005 \%$ bovine serum albumin) in a total volume of $5 \mu \mathrm{l}$ using 384 -well plates. The concentrations of human or rat RIP2 catalytic domain (1-305 amino acids; Carna Biosciences, Inc., Hyogo, Japan) and ATP were 1.2 or $2 \mu \mathrm{g} / \mathrm{ml}$ and $10 \mu \mathrm{M}$, respectively. The Km of ATP for human RIP2 was approximately $90 \mu \mathrm{M}$ (data not shown). RIP2 was incubated with ATP and various concentrations of AS3334034 in assay buffer at room temperature for 30 minutes. Kinase activities were measured using the luminescence-based ADP-Glo Kinase assay kit (Promega, Madison, WI) in accordance with the manufacturer's protocol. The luminescence was measured by an EnVision plate reader (PerkinElmer, Waltham, MA).

Muramyl Dipeptide-Stimulated NF- $\mathrm{B}$ Luciferase Reporter Assay. The human colorectal cancer cell line HCT116 was obtained from American Type Culture Collection (Manassas, VA) and cultured at $37^{\circ} \mathrm{C}$ in a $5 \% \mathrm{CO}_{2}$ humidified atmosphere in Dulbecco's modified Eagle's medium supplemented with $10 \%$ fetal calf serum. An NF- $\kappa$ B luciferase reporter construct was stably integrated into HCT116 cells using a firefly luciferase reporter pGL4.32[luc2P/NF- $\kappa$ B-RE/Hygro] vector obtained from Promega. After transfection using Lipofectamine transfection reagent (Invitrogen, Carlsbad, CA) in accordance with the manufacturer's protocol, the stable cell line was generated by selection using Hygromycin. All experiments were performed with mycoplasma-free cells. Cells were seeded at a density of 10,000 cells using 384-well plates and treated the following day with various concentrations of AS3334034. After 5 minutes, $150 \mu \mathrm{g} / \mathrm{ml}$ of muramyl dipeptide (MDP; Peptide Institute, Inc., Osaka, Japan), the NOD2 ligand, was added in a total volume of $40 \mu \mathrm{l}$ and incubated for 4 hours at $37^{\circ} \mathrm{C}$. Luciferase activity was quantified using the Steady-Glo luciferase detection reagent (Promega) in accordance with the manufacturer's protocol. The luminescence was measured by an EnVision plate reader.

Kinase Selectivity Assay. Pharmacological screening assays for various kinases were performed at $1 \mu \mathrm{M}$ of AS3334034 using kinase profiling services according to standard assay procedures specified by 
Carna Biosciences, Inc. The kinase profiling was performed at ATP concentrations approximately equal to the $\mathrm{Km}$ values.

Pharmacokinetics. AS3334034 $(10 \mathrm{mg} / \mathrm{kg})$ was administered orally to CKD rats once daily for 4 weeks, and blood samples were drawn from the tail vein before dosing, and at $0.5,1,3$, and 8 hours after dosing. The plasma concentration of drug was measured by liquid chromatography-tandem mass spectrometry following protein precipitation with acetonitrile. Pharmacokinetic parameters were calculated from mean plasma AS3334034 concentrations using the noncompartmental analysis model of Phoenix WinNonlin version 7.0 software (Certara USA, Inc., Princeton, NJ).

MDP-Induced Increase in Plasma MCP-1 Level in Rats. Normal rats were randomly divided into the following groups: vehicle administration to normal rats (control) and vehicle or AS3334034 $(3-30 \mathrm{mg} / \mathrm{kg}$ ) administration to MDP-treated rats ( $n=4$ each group). AS3334034 (3-30 mg/kg) was administered orally to normal rats, and blood samples were collected from the abdominal vena cava under isoflurane anesthesia at 3, 8, and 24 hours after dosing. L18-MDP $(10 \mu \mathrm{g} / 0.5 \mathrm{ml}$ saline/rat; InvivoGen, San Diego, CA), a synthetic derivative of MDP with higher potency, was intraperitoneally injected at 2 hours before each blood sampling. Saline was intraperitoneally injected to control rats. Plasma concentrations of MCP-1 were measured using a commercial enzyme-linked immunosorbent assay (ELISA) kit (SMJE00; R\&D Systems Inc., Minneapolis, MN).

Effect of Repeated Administration of AS3334034 in CKD Rats. CKD rats were randomly divided into weight-matched groups. Group composition was as follows: vehicle administration to normal rats (normal, $n=6$ ); vehicle administration to $\mathrm{Nx}$ rats $(\mathrm{Nx}, n=6)$; and vehicle (vehicle, $n=8)$, AS3334034 (10 $\mathrm{mg} / \mathrm{kg}, n=8)$, or losartan administration $(30 \mathrm{mg} / \mathrm{kg}, n=8)$ to $\mathrm{Nx}$ adriamycin-treated CKD rats. Each drug was administered orally to CKD rats once daily for 6 weeks. Body weights were measured every week. At weeks 2, 4, and 6, rats were transferred to metabolic cages, spontaneously voided urine was collected for 24 hours, food consumption was measured, and blood samples were obtained from the tail vein. Plasma MCP-1 levels were measured using blood samples at week 2 of repeated administration using the commercial ELISA kit (R\&D Systems Inc.). After the final drug administration at week 6 , blood samples were collected from the abdominal vena cava under isoflurane anesthesia, and the right kidney was isolated. The renal tissues were immersed in $10 \%$ neutralbuffered formalin for histologic evaluation. Blood samples were centrifuged (15,000 rpm, 10 minutes), and the supernatant was used to measure several parameters. Urinary protein concentrations were measured using a protein assay reagent (Bio-Rad Laboratories, Inc., Hercules, CA). Plasma and urinary creatinine and blood urea nitrogen (BUN) levels were measured using a Hitachi 7180 automatic analyzer (Hitachi High-Technologies Corporation, Tokyo, Japan). Creatinine clearance was calculated using the following equation: Creatinine clearance $(\mathrm{ml} / \mathrm{min})=$ [urinary creatinine $(\mathrm{mg} / \mathrm{dl}) \times 24$ hours urine volume $(\mathrm{ml}) / 1440(\mathrm{~min})] /$ plasma creatinine $(\mathrm{mg} / \mathrm{dl})$. Additional studies on renal apoptosis, glomerular podocyte injury, and histologic evaluation at week 4 were investigated by repeating a whole experiment independently with the same experimental method. Group composition was as follows: 1 ) vehicle in normal rats (normal, $n=6$ ), 2) vehicle in Nx adriamycin-treated CKD rats (vehicle, $n=9$ ), and 3) AS3334034 in $\mathrm{Nx}$ adriamycin-treated $\mathrm{CKD}$ rats $(10 \mathrm{mg} / \mathrm{kg}, n=9)$. Urinary podocalyxin concentrations were measured in urine samples at week 2 of repeated administration using a commercial ELISA kit (Exocell, Inc., Philadelphia, PA). Renal tissues after final drug administration at week 4 were collected for histologic evaluation.

Histopathology. Specimen preparation and histopathological examination were performed at CMIC Bioresearch Center Co., Ltd. (Yamanashi, Japan). Sagittal slices of renal tissue were fixed in $10 \%$ neutral-buffered formalin, embedded in paraffin, and cut into 2 - $\mu \mathrm{m}$-thick sections for morphologic study. These sections were stained with hematoxylin and eosin, periodic acid Schiff, terminal deoxynucleotidyl transferase-mediated digoxigenin-deoxyuridine nick-end labeling (TUNEL: ApopTag Peroxidase In Situ Apoptosis Detection Kit;
EMD Millipore Corporation., Burlington, MA), or anti-Wilms' tumor 1 (WT-1) antibody (clone: 6F-H2; Nichirei Biosciences Inc., Tokyo, Japan). WT-1 staining was performed in accordance with the method as previously described (Wada et al., 2016). All tissue samples were evaluated by an independent investigator blinded to group information. All glomeruli and the entire microscopic area in each specimen were examined. Histopathological changes (glomerulosclerosis, interstitial fibrosis, interstitial mononuclear cell infiltration, basophilic change, and tuft adhesions to Bowman's capsule) were evaluated using a semiquantitative scoring system according to the percentage of affected renal tissue as follows: 0 : no lesion, 1 : very slight $(<10 \%), 2$ : slight $(10 \% \leq \mathrm{X}<$ $25 \%)$, 3: moderate $(25 \% \leq \mathrm{X}<50 \%$ ), and 4 : marked ( $\geq 50 \%)$. The number of TUNEL-positive cells was counted per 10 randomly selected field cross-sections, and the mean value was calculated. The number of WT-1-positive cells per glomerulus was counted per 10 randomly selected glomeruli cross-sections, and the mean value was calculated.

Statistical Analysis. The experimental results are expressed as means with S.D. or S.E.M. or scatter plots with mean or median. To determine the $50 \%$ inhibitory concentration $\left(\mathrm{IC}_{50}\right)$ values with $95 \%$ confidence interval, a sigmoid-concentration response curve was plotted using GraphPad Prism 7 (GraphPad Software, La Jolla, CA). The significance of differences between two groups was determined using two-tailed unpaired $t$ test, whereas one-way ANOVA with Tukey's or Dunnett's multiple comparisons test was used for comparisons between multiple groups. Before testing for statistical significance, Grubb's test was employed to detect outliers in plasma creatinine because some individuals exhibited outliers, and logarithmic transformation was performed for BUN because the range of variation was large. To compare histopathological scores, the significance of differences between two groups was determined using two-tailed Mann-Whitney test, whereas Kruskal-Wallis test with Dunn's multiple comparisons test was used for comparisons between multiple groups. Pearson correlation analysis was performed to examine the relationship between log10-transformed plasma MCP-1 levels and renal functional parameters. Spearman correlation analysis was performed to examine the relationship between log10-transformed plasma MCP-1 levels and renal histopathological scores. A value of $P<0.05$ was considered to be statistically significant. Statistical and data analyses were conducted using GraphPad Prism 7.

\section{Results}

In Vitro Pharmacological Characterization of AS3334034. AS3334034 potently inhibited rat and human RIP2 kinase activity, with $\mathrm{IC}_{50}$ values of $3.02 \pm 0.30$ and $2.10 \pm 0.73 \mathrm{nM}$, respectively. AS3334034 concentration-dependently inhibited MDP-induced NF- $\kappa \mathrm{B}$ activation in $\mathrm{HCT} 116$ cells, with an $\mathrm{IC}_{50}$ value of 4.4 (95\% confidence interval, 3.6-5.3) $\mathrm{nM}$ (Fig. 2).

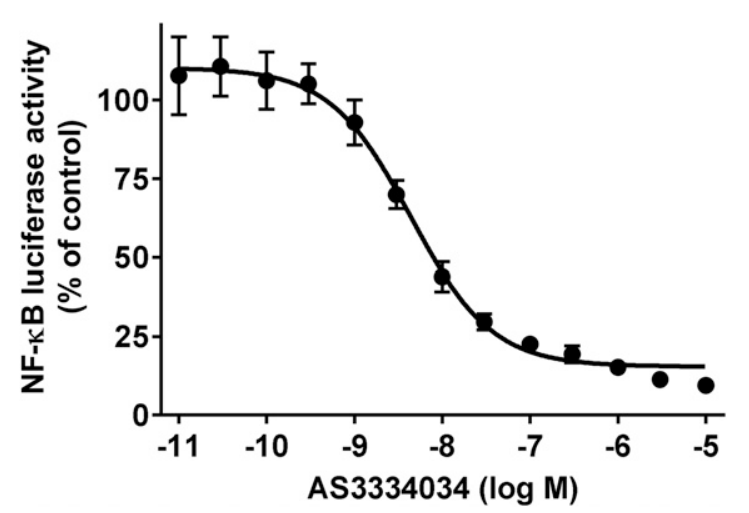

Fig. 2. Effect of AS3334034 on MDP-induced NF- $\kappa \mathrm{B}$ activation in HCT116 cells. NF- $\kappa$ B luciferase activity was normalized relative to MDP control $(100 \%)$ and unstimulated control $(0 \%)$. The values are expressed as means \pm S.D. of six independent experiments performed in duplicate. 
TABLE 1

Kinase selectivity profile of AS3334034

Kinase assays were performed at $1 \mu \mathrm{M}$ of AS3334034.

\begin{tabular}{|c|c|c|c|c|c|}
\hline Kinase & $\%$ inhibition & Kinase & $\%$ inhibition & Kinase & $\%$ inhibition \\
\hline $\mathrm{ABL}$ & 49 & RET & 25 & $\operatorname{IKK} \alpha$ & NI \\
\hline $\mathrm{ALK}$ & NI & SRC & 68 & $\operatorname{IKK} \beta$ & $\mathrm{NI}$ \\
\hline BTK & 28 & SYK & NI & IRAK4 & $\mathrm{NI}$ \\
\hline CSK & 32 & TIE2 & $\mathrm{NI}$ & JNK1 & $<10$ \\
\hline DDR1 & 73 & TRKA & 32 & JNK2 & $<10$ \\
\hline DDR2 & 62 & TYK2 & $<10$ & JNK3 & NI \\
\hline EGFR & 35 & TYRO3 & NI & MAPKAPK2 & NI \\
\hline EPHA2 & 62 & YES & 60 & MSK1 & NI \\
\hline EPHB4 & 81 & $\mathrm{AKT} 1$ & NI & MST1 & $<10$ \\
\hline FAK & $<10$ & AKT2 & NI & NEK2 & $\mathrm{NI}$ \\
\hline FGFR1 & $<10$ & $\mathrm{AMPK} \alpha 1 / \beta 1 / \gamma 1$ & NI & p38 $\beta$ & 17 \\
\hline FLT3 & $<10$ & AurA & NI & p70S6K & NI \\
\hline IGFR1 & NI & CaMK4 & NI & PAK2 & $<10$ \\
\hline INSR & NI & CDK2/CycA2 & NI & PBK & NI \\
\hline ITK & NI & CDK5/p25 & NI & PIM1 & NI \\
\hline JAK1 & NI & CHK1 & $<10$ & $\operatorname{PKAC} \alpha$ & NI \\
\hline JAK2 & $<10$ & $\mathrm{CK} 1 \varepsilon$ & $<10$ & $\mathrm{PKC} \alpha$ & NI \\
\hline JAK3 & $<10$ & DAPK1 & $<10$ & $\operatorname{PKC} \theta$ & NI \\
\hline KDR & 13 & DYRK1B & NI & PKD2 & NI \\
\hline KIT & 17 & Erk1 & NI & ROCK1 & NI \\
\hline LCK & 53 & Erk2 & NI & SGK & NI \\
\hline MET & NI & GSK3 $\beta$ & 30 & TBK1 & NI \\
\hline $\operatorname{PDGFR} \alpha$ & 68 & HGK & $<10$ & & \\
\hline PYK2 & $<10$ & HIPK1 & NI & & \\
\hline
\end{tabular}

DDR, discoidin domain receptor; EPH, ephrin receptor; MAPK, mitogen-activated protein kinse; NI, not inhibited. Abbreviations and other detailed information on kinases are described by Carna Biosciences, Inc. or in Kitagawa et al. (2013).

In addition, $1 \mu \mathrm{M}$ of AS3334034 only partially inhibited several kinase activities, such as discoidin domain receptor and ephrin receptor, and had little effects on various other kinase activities, although the concentration is approximately 480-fold greater than the $\mathrm{IC}_{50}$ value of $\mathrm{AS} 3334034$ in human RIP2 kinase assay (Table 1).

Pharmacokinetics. After oral administration of AS3334034 (10 $\mathrm{mg} / \mathrm{kg}$ ) to CKD rats to which the drug had been repeatedly administered for 4 weeks, the plasma concentration of unchanged drug was measured, showing that it rapidly reached a maximum at 0.5 hour (Fig. 3). The corresponding $\mathrm{C}_{\max }$ was $6830 \mathrm{ng} / \mathrm{ml}$, and the area under the curve between 0 and 24 hours was $26,300 \mathrm{ng} \cdot \mathrm{h} / \mathrm{ml}$.

Effect of Single Administration of AS3334034 on MDP-Induced Increase in Plasma MCP-1 Level. Compared with the control group, the L18-MDP (10 $\mu \mathrm{g} / \mathrm{rat})$-treated vehicle group showed a significant increase in plasma MCP-1 levels (Fig. 4). AS3334034 (3-30 mg/kg) dose-dependently inhibited this MDP-induced increase in plasma MCP-1 levels. This inhibitory effect significantly lasted for 8 hours at doses of $3 \mathrm{mg} / \mathrm{kg}$ or higher and for 24 hours at doses of $30 \mathrm{mg} / \mathrm{kg}$.

Effect of Repeated Administration of AS3334034 in CKD Rats. Compared with normal rats, CKD rats showed a progressive increase in urinary protein excretion (Fig. 5A; Table 3). Repeated administration of AS3334034 (10 mg/kg) significantly suppressed this elevated urinary protein excretion. In contrast, losartan $(30 \mathrm{mg} / \mathrm{kg})$ did not significantly attenuate urinary protein excretion. In addition, CKD rats exhibited significant increases in plasma levels of creatinine and BUN and a decrease in creatinine clearance (Fig. 5, B-D; Table 3). AS3334034 significantly improved these parameters, whereas losartan did not. CKD rats showed decreased body weight compared with normal rats (Table 2). Repeated administration of AS3334034 significantly improved this weight loss without affecting food intake. Losartan tended to improve this weight loss although the effect was not significant. In addition, CKD rats exhibited significant glomerulosclerosis, interstitial fibrosis, basophilic change, interstitial mononuclear cell infiltration, and tuft adhesions to Bowman's capsule (week 6: Fig. 6, week 4: Supplemental Fig. 1). Renal tubules around the glomeruli were severely degenerated, and the tubular lumen were dilated. Marked infiltration of inflammatory cells was observed in the interstitium, and mild fibrosis was present. AS3334034 significantly attenuated or tended to attenuate these pathologic changes. Compared with normal rats, CKD rats exhibited a significant increase in plasma MCP-1 levels (Fig. 7). Repeated administration of AS3334034 significantly reduced plasma MCP-1 levels. Losartan also tended to reduce plasma MCP-1 levels, although this effect was not significant. In addition, significant correlations were seen between plasma

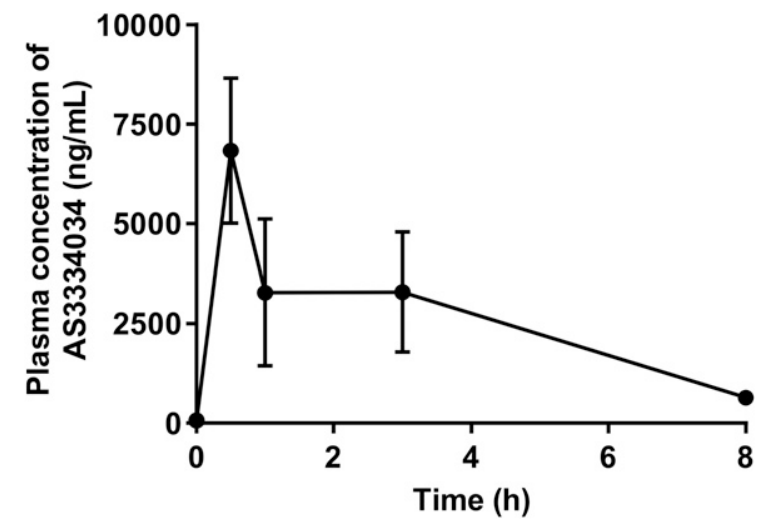

Fig. 3. Pharmacokinetics of AS3334034 in CKD rats. AS3334034 (10 mg/kg) was orally administered to $\mathrm{Nx}$ adriamycin-treated CKD rats for 4 weeks, and the time-course of changes in AS3334034 plasma concentrations was measured before ( 0 hour) and after dosing. Each data point is expressed as mean \pm S.D. for three animals. 


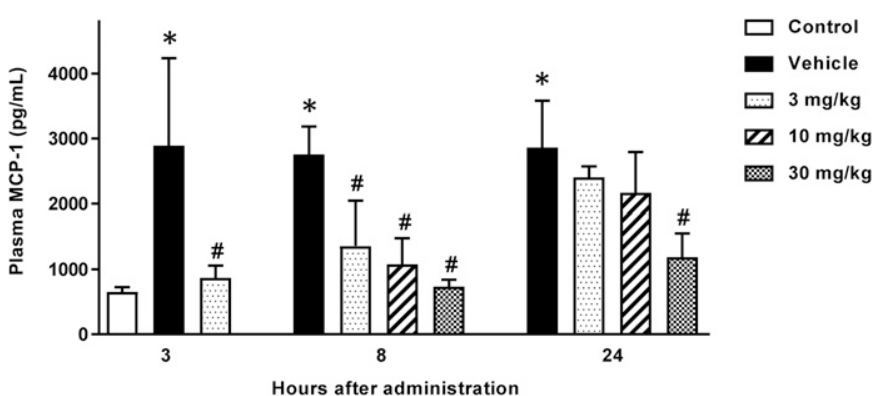

Fig. 4. Effect of AS3334034 on MDP-induced increase in plasma MCP-1 level in rats. Vehicle or AS3334034 was orally administered to normal rats, and blood samples were collected at 3, 8, and 24 hours after dosing. L18-MDP (10 $\mu \mathrm{g} / 0.5 \mathrm{ml}$ saline/rat), a synthetic derivative of MDP, was intraperitoneally injected at 2 hours before blood sampling. Saline was intraperitoneally injected to control rats. The values are means \pm S.D. for four animals in each group. Two-tailed unpaired $t$ test was used for comparisons between normal and vehicle groups, and two-tailed unpaired $t$ test (3 hours) or one-way ANOVA with Dunnett's multiple comparisons test ( 8 hours and 24 hours) was used for comparisons between vehicle and AS3334034 groups. $* P<0.05$ vs. control group, ${ }^{\#} P<0.05$ vs. vehicle group.

MCP-1 level and parameters of renal function and injury (plasma creatinine levels, urinary protein excretion, glomerulosclerosis, and interstitial fibrosis). In additional studies for podocyte injury and renal apoptosis, compared with normal rats, CKD rats exhibited a significant decrease in WT-1-positive cells in glomeruli and a significant increase in urinary podocalyxin excretion-both markers of glomerular podocyte injury - and a significant increase in TUNEL-positive cells as a marker of apoptosis (Fig. 8; Supplemental Fig. 2).
Repeated administration of AS3334034 significantly attenuated changes in these parameters.

\section{Discussion}

The present study characterized the pharmacological profile of AS3334034, a newly discovered potent and selective RIP2 inhibitor, and showed the renoprotective effects of AS3334034 in uninephrectomized adriamycin-induced CKD rats.

A large body of experimental and clinical evidence has supported the view that a chronic inflammatory state exists in CKD and that this state is further heightened in ESRD, strongly contributing to morbidity and mortality (Carrero and Stenvinkel, 2009). Although multiple inflammatory factors may be involved in initiating and orchestrating the development of $\mathrm{CKD}$, the factors that trigger the inflammatory cascade are still not well recognized. NOD proteins have been reported to potentially underlie the pathophysiology of CKD, including diabetic nephropathy, and renal failure induced by a variety of bacterial Toll-like receptor ligands, such as peptidoglycans and lipopolysaccharide, via the production of proinflammatory cytokines and renal inflammation (Stroo et al., 2012; Du et al., 2013). In addition, the NOD-RIP2 pathway has been shown to contribute to acute kidney failure in ischemia reperfusion injury (Shigeoka et al., 2010). These findings support an essential role of the NOD-RIP2 pathway in cellular signaling to produce proinflammatory cytokines, including MCP-1, as a possible mechanism underlying the pathogenesis of kidney diseases. RIP2 might therefore be a promising target
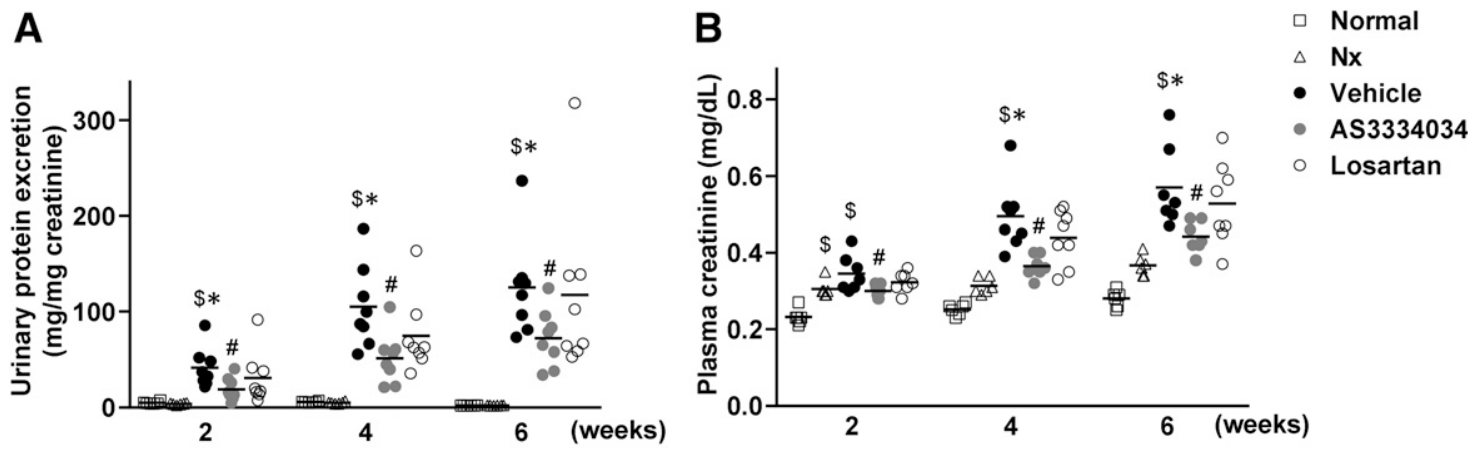

C
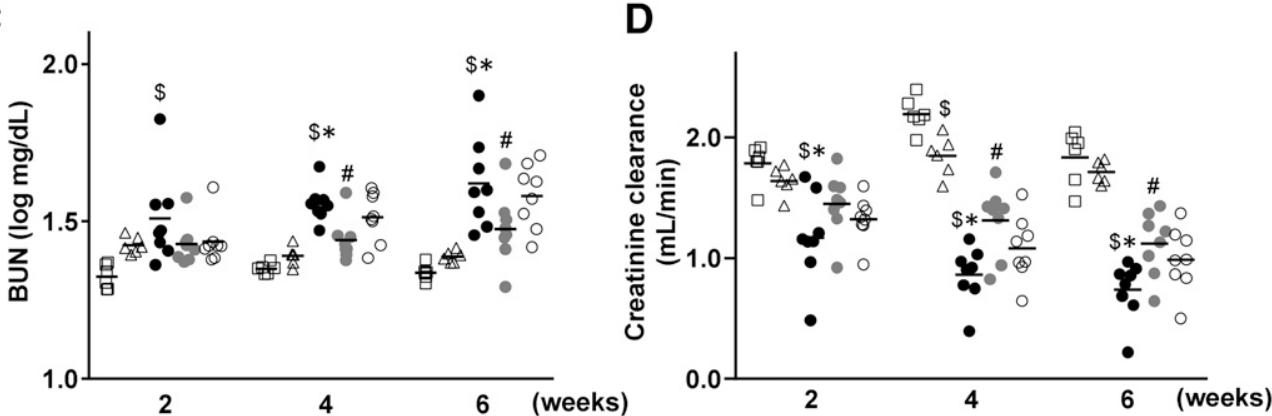

Fig. 5. Effects of 6 weeks' repeated administration of AS3334034 on renal function in CKD rats. Time course of changes in urinary protein excretion (A), levels of plasma creatinine (B) and BUN (C), and creatinine clearance (D). Vehicle, AS3334034 (10 mg/kg), or losartan (30 mg/kg) was orally administered to Nx adriamycin-treated CKD rats once daily for 6 weeks. For the control, vehicle was orally administered to normal or nephrectomized rats. Results are displayed using scatter plots with mean values for six animals in the normal and Nx groups and eight animals in the other groups. One-way ANOVA with Tukey's multiple comparisons test was used for comparisons between normal, Nx, and vehicle groups, and two-tailed unpaired $t$ test was used for comparisons between vehicle and each drug group. ${ }^{\$} P<0.05$ vs. normal group, ${ }^{*} P<0.05$ vs. Nx group, ${ }^{\#} P<0.05$ vs. vehicle group. 
TABLE 2

Effect of repeated administration of AS3334034 on body weight in CKD rats AS3334034 and losartan were orally administered to CKD rats once daily for 6 weeks.

\begin{tabular}{|c|c|c|c|c|c|c|}
\hline & & Normal & $\mathrm{Nx}$ & Vehicle & AS3334034 & Losartan \\
\hline Week 0 & Body weight (g) & $170 \pm 4$ & $199 \pm 4$ & $199 \pm 3$ & $199 \pm 3$ & $199 \pm 3$ \\
\hline \multirow[t]{2}{*}{ Week 2} & Body weight (g) & $244 \pm 6$ & $261 \pm 6$ & $220 \pm 6^{\$ *}$ & $236 \pm 5$ & $226 \pm 4$ \\
\hline & Food intake (g/day) & $17.5 \pm 0.7$ & $18.0 \pm 0.9$ & $14.5 \pm 0.9^{*}$ & $14.1 \pm 1.1$ & $13.8 \pm 0.7$ \\
\hline \multirow[t]{2}{*}{ Week 4} & Body weight $(\mathrm{g})$ & $286 \pm 5$ & $298 \pm 7$ & $232 \pm 9^{\$ *}$ & $263 \pm 8^{\#}$ & $247 \pm 8$ \\
\hline & Food intake (g/day) & $16.2 \pm 0.3$ & $15.3 \pm 0.8$ & $14.3 \pm 0.8$ & $14.1 \pm 0.6$ & $13.0 \pm 0.7$ \\
\hline \multirow[t]{2}{*}{ Week 6} & Body weight $(\mathrm{g})$ & $314 \pm 6$ & $321 \pm 7$ & $243 \pm 10^{\$ *}$ & $277 \pm 8^{\#}$ & $261 \pm 9$ \\
\hline & Food intake (g/day) & $15.3 \pm 0.8$ & $15.5 \pm 1.1$ & $13.4 \pm 1.5$ & $14.6 \pm 1.3$ & $15.4 \pm 1.1$ \\
\hline
\end{tabular}

Values are means \pm S.E.M. for six to eight animals per group. One-way ANOVA with Tukey's multiple comparisons test was used for comparisons between normal, Nx, and vehicle groups, and two-tailed unpaired $t$ test was used for comparisons between vehicle and each drug group at weeks 2,4 , and 6 .

${ }_{\$} P<0.05$ vs. normal group; ${ }^{*} P<0.05$ vs. Nx group; ${ }^{\#} P<0.05$ vs. vehicle group.

for treatment of inflammatory kidney diseases, including CKD. In the present study, the RIP2 inhibitor AS3334034 was shown to suppress the progression of chronic renal failure via an anti-inflammatory effect and is, therefore, suggested to be useful in treating patients with CKD.

AS3334034 potently inhibited rat and human RIP2 kinase activities with $\mathrm{IC}_{50}$ values in the nanomolar range but did not potently inhibit various other kinase activities. AS3334034 is thus likely to possess potent inhibitory activity and selectivity for RIP2, although the effects against additional kinases, including broader kinases, require investigation. In accordance with reports showing that RIP2 autophosphorylation is critical for MDP-induced NF- $\kappa \mathrm{B}$ activation (Dorsch et al., 2006; Yang et al., 2007; Tigno-Aranjuez et al., 2010; Nachbur et al., 2015), the RIP2 inhibitor AS3334034 concentrationdependently inhibited MDP-induced NF- $\kappa$ B activation in HCT116 cells. Our present result that AS3334034 showed an inhibitory effect on MDP-induced MCP-1 secretion in rats is also consistent with the report that MDP-induced NOD signal activation was thoroughly abolished in RIP2 knockdown (Magalhaes et al., 2011). Thus, RIP2 is likely to play pivotal roles in proinflammatory cytokine production and inflammatory responses. AS3334034 is expected to be a specific longlasting RIP2 inhibitor that is useful in attenuating renal inflammatory responses in vivo.

In uninephrectomized adriamycin-induced CKD rats, levels of plasma creatinine and BUN and urinary protein excretion were progressively elevated, accompanied by a marked decrease in creatinine clearance as well as pathologic changes, which are similar to those observed in patients with CKD. In addition, CKD rats exhibited renal cell damages, such as renal apoptosis as demonstrated by TUNEL-positive staining in tubular epithelial cells (Supplemental Fig. 2), and glomerular podocyte injury as demonstrated by a decrease in the number of WT-1-positive cells and urinary podocalyxin excretion. Podocytes are an essential component of the renal glomerular filtration barrier, whose detachment and loss leads to adhesion between the glomerular tuft and Bowman's capsule and glomerulosclerosis, which in turn lead to proteinuric kidney disease. RIP2 has been shown to play a crucial role in cell apoptosis as well as in NF- $\kappa \mathrm{B}$ activation (Inohara et al., 1998; McCarthy et al., 1998). In addition, NOD2 has been suggested to be a critical component in the signal transduction pathway that links glomerular podocyte injury via renal inflammation (Du et al., 2013). The NOD-RIP2 axis seems to play a key role in deregulated innate immunity (Hato and Dagher, 2015), probably in nonimmune cells such as podocytes and tubular epithelial cells. The excessive activation of this axis may induce deleterious effects on these cells via proinflammatory and proapoptotic processes and in turn orchestrate the development of renal tissue injury. In the present study, AS3334034 consistently improved renal inflammation, apoptosis, podocyte injury, adhesion between the glomerular tuft and Bowman's capsule, glomerulosclerosis, and interstitial fibrosis. Accordingly, the inhibition of the NOD-RIP2 cascade by AS3334034 is suggested to confer beneficial effects on renal pathologic changes via anti-inflammation, antiapoptosis, and the suppression of podocyte damage.

Increased circulating levels of proinflammatory cytokines, such as tumor necrosis factor $\alpha$ (TNF- $\alpha$ ) and MCP-1, have been described in patients with CKD (Pereira et al., 1994; Stinghen et al., 2009); these proinflammatory cytokines presumably

TABLE 3

Effects of repeated administration of AS3334034 on renal function in CKD rats

\begin{tabular}{|c|c|c|c|c|c|c|}
\hline & & Normal & $\mathrm{Nx}$ & Vehicle & AS3334034 & Losartan \\
\hline \multirow[t]{3}{*}{ Urinary protein excretion (mg/mg creatinine) } & Week 2 & $4.9 \pm 0.5$ & $3.6 \pm 0.4$ & $41 \pm 7^{\$ *}$ & $19 \pm 4^{\#}$ & $31 \pm 10$ \\
\hline & Week 4 & $5.7 \pm 0.3$ & $4.8 \pm 0.4$ & $105 \pm 15^{\$ *}$ & $51 \pm 9^{\#}$ & $75 \pm 14$ \\
\hline & Week 6 & $2.0 \pm 0.1$ & $2.1 \pm 0.1$ & $125 \pm 18^{\$ *}$ & $72 \pm 11^{\#}$ & $117 \pm 31$ \\
\hline \multirow{3}{*}{ Plasma creatinine $(\mathrm{mg} / \mathrm{dl})$} & Week 2 & $0.23 \pm 0.01$ & $0.31 \pm 0.01^{\$}$ & $0.35 \pm 0.02^{\$}$ & $0.30 \pm 0.01^{\#}$ & $0.32 \pm 0.01$ \\
\hline & Week 4 & $0.25 \pm 0.01$ & $0.31 \pm 0.01$ & $0.50 \pm 0.03^{\$ *}$ & $0.36 \pm 0.01^{\#}$ & $0.44 \pm 0.03$ \\
\hline & Week 6 & $0.28 \pm 0.01$ & $0.37 \pm 0.01$ & $0.57 \pm 0.04^{\$ *}$ & $0.44 \pm 0.02^{\#}$ & $0.53 \pm 0.04$ \\
\hline \multirow[t]{3}{*}{ BUN (log mg/dl) } & Week 2 & $1.32 \pm 0.02$ & $1.42 \pm 0.01$ & $1.51 \pm 0.05^{\$}$ & $1.43 \pm 0.02$ & $1.44 \pm 0.03$ \\
\hline & Week 4 & $1.35 \pm 0.01$ & $1.39 \pm 0.01$ & $1.56 \pm 0.02^{\$ *}$ & $1.44 \pm 0.02^{\#}$ & $1.51 \pm 0.03$ \\
\hline & Week 6 & $1.34 \pm 0.01$ & $1.39 \pm 0.01$ & $1.62 \pm 0.05^{\$ *}$ & $1.48 \pm 0.04^{\#}$ & $1.58 \pm 0.04$ \\
\hline \multirow{3}{*}{ Creatinine clearance $(\mathrm{ml} / \mathrm{min})$} & Week 2 & $1.79 \pm 0.06$ & $1.64 \pm 0.05$ & $1.17 \pm 0.13^{\$ *}$ & $1.45 \pm 0.09$ & $1.32 \pm 0.07$ \\
\hline & Week 4 & $2.19 \pm 0.06$ & $1.85 \pm 0.07^{\$}$ & $0.86 \pm 0.08^{\$ *} *$ & $1.31 \pm 0.10^{\#}$ & $1.08 \pm 0.09$ \\
\hline & Week 6 & $1.83 \pm 0.09$ & $1.71 \pm 0.04$ & $0.74 \pm 0.09^{\$ *}$ & $1.12 \pm 0.09^{\#}$ & $0.98 \pm 0.09$ \\
\hline
\end{tabular}

${ }^{\$} P<0.05$ vs. normal group; ${ }^{*} P<0.05$ vs. Nx group; ${ }^{\#} P<0.05$ vs. vehicle group. 
A

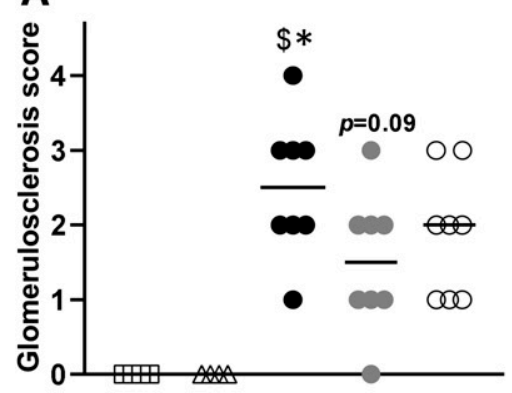

C

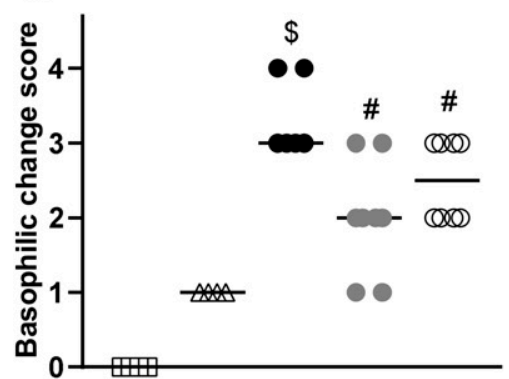

B

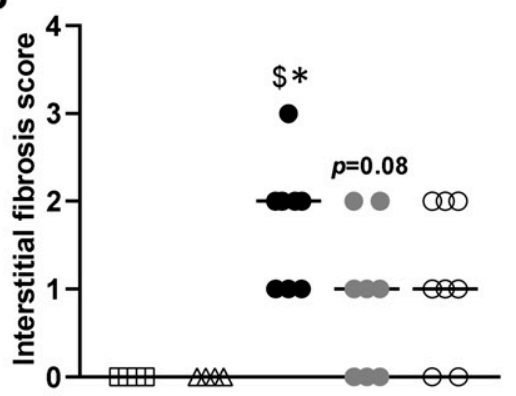

D

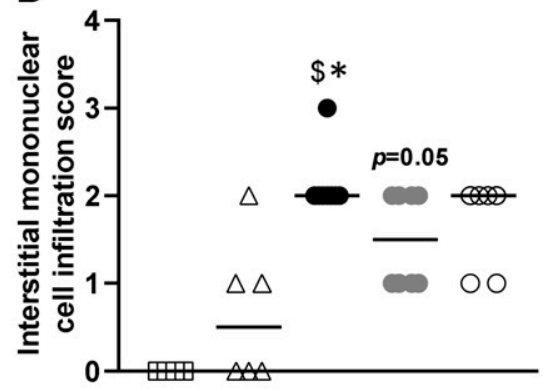

Normal

$\triangle N \mathbf{N}$

- Vehicle

- AS3334034

○ Losartan
$F$

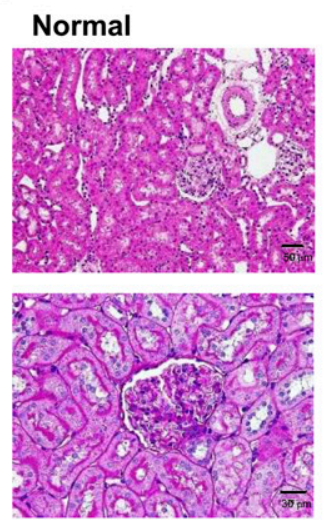

Nx
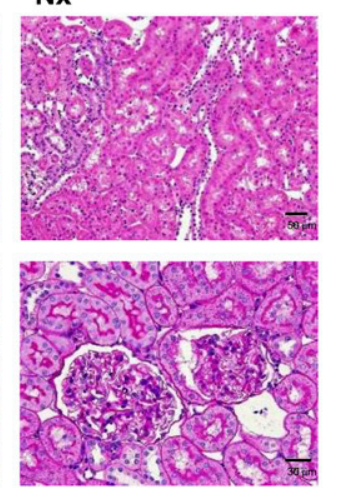

Vehicle
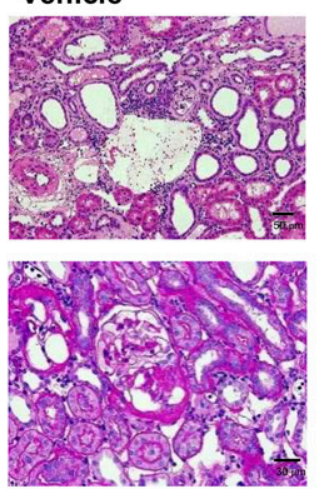

E

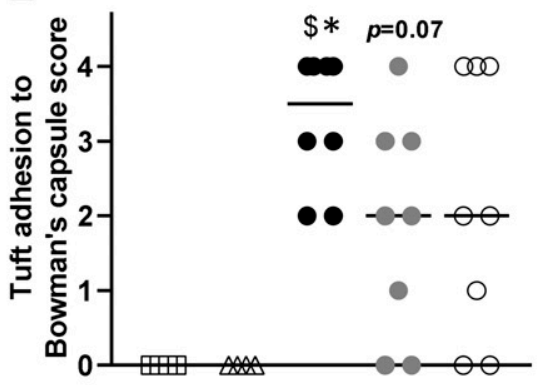

Fig. 6. Improvement in renal injury by 6 weeks' repeated administration of AS3334034 in CKD rats. AS3334034 (10 mg/kg) or losartan ( $30 \mathrm{mg} / \mathrm{kg}) \mathrm{was}$ orally administered to $\mathrm{Nx}$ adriamycin-treated CKD rats for 6 weeks. Histopathological scores of glomerulosclerosis (A), interstitial fibrosis (B), basophilic change (C), interstitial mononuclear cell infiltration (D), and tuft adhesion to Bowman's capsule (E). Results are displayed using scatter plots with median values for six animals in the normal and Nx groups and eight animals in the other groups. Kruskal-Wallis test with Dunn's multiple comparisons test was used for comparisons between normal, $\mathrm{Nx}$, and vehicle groups, and two-tailed Mann-Whitney test was used for comparisons between vehicle and each drug group. ${ }^{\$} P<0.05$ vs. normal group, ${ }^{*} P<0.05$ vs. Nx group, ${ }^{\#} P<0.05$ vs. vehicle group. (F) Representative light micrographs. Hematoxylin and eosin (upper) and periodic acid Schiff (lower) stain. Scale bars in the upper and lower panels show 50 and $30 \mu \mathrm{m}$, respectively.

participate in pathways that segment the inflammatory cascade and, in turn, induce renal injury. In the present study, CKD rats displayed elevated plasma levels of MCP-1, suggesting a chronic inflammatory condition. This inflammatory condition was significantly attenuated by AS3334034. Renal inflammation occurs with infiltration of mononuclear cells, including macrophages, into kidney interstitium, an effect of which was also attenuated by AS3334034. These renoprotective and anti-inflammatory effects of AS3334034 in CKD rats were significant at a dose of $10 \mathrm{mg} / \mathrm{kg}$, which is consistent with the results obtained in the MDP-induced MCP-1 secretion study. NOD2 deficiency has been reported to ameliorate the activation of various inflammatory cytokines, such as MCP-1, TNF- $\alpha$, IL-6, IL-8, and IL- $1 \beta$, in the kidney of diabetic model mice (Du et al., 2013). In addition, plasma levels of MCP- 1 and TNF- $\alpha$ have been shown to be significantly elevated in patients with $\mathrm{CKD}$, in association with the prevalence and severity of CKD (Lee et al., 2015; Gregg et al., 2018). Although the effects of AS3334034 on inflammatory cytokines other than MCP-1 have not yet been investigated, the inhibition of the NODRIP2-NF- $\kappa$ B cascade by AS3334034 would suppress the progression of chronic renal failure, at least in part, via attenuating the inflammatory state.

Inflammation is closely associated with the generation of profibrotic factors and a decline in glomerular filtration rate (Fried et al., 2004; Lebleu et al., 2008; Lv et al., 2018). Indeed, anti-inflammatory agents such as corticosteroids (Pozzi et al., 2013), curcumin (Ghosh et al., 2012), and pentoxifylline (Lin et al., 2005) reduce inflammation and slow the progression of CKD. In the present results, statistically significant correlations 
A

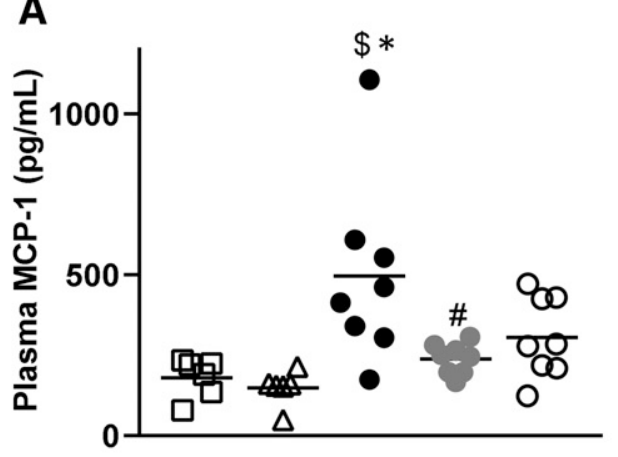

\author{
$\square$ Normal \\ $\triangle \mathrm{Nx}$ \\ - Vehicle \\ - AS3334034 \\ O Losartan
}

B

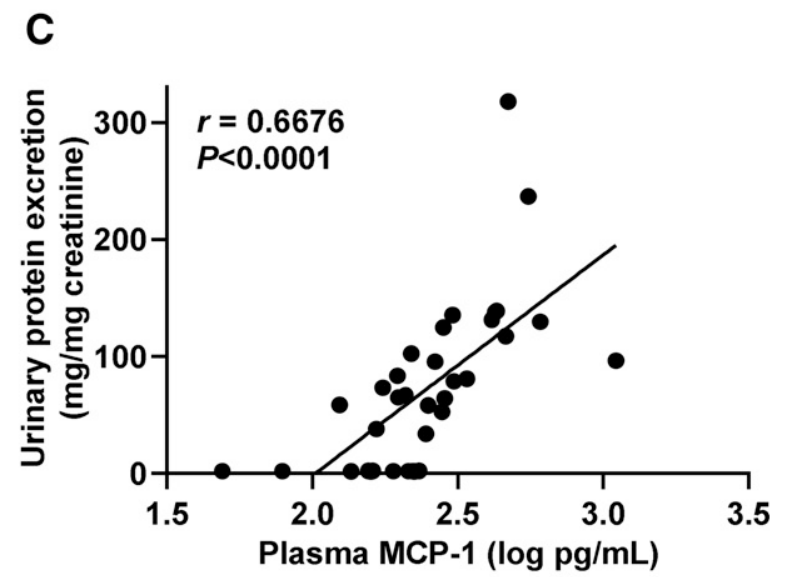

D

E
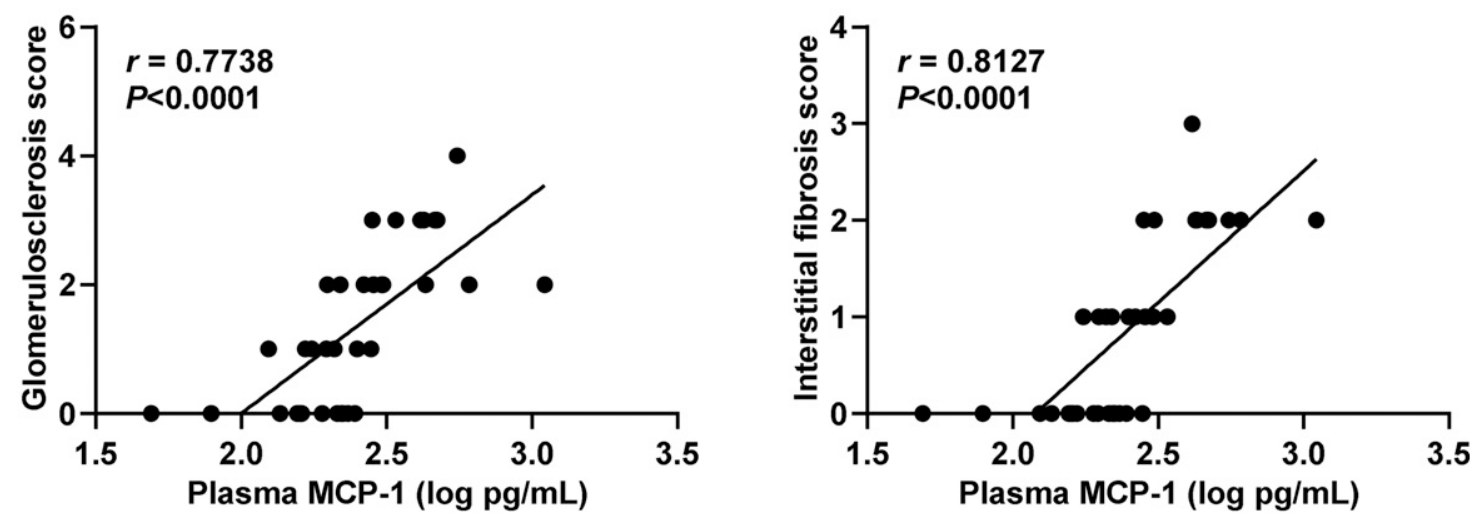

Fig. 7. (A) Effect of repeated administration of AS3334034 on plasma MCP-1 levels in CKD rats. AS3334034 (10 mg/kg) or losartan (30 mg/kg) was orally administered to Nx adriamycin-treated CKD rats for 6 weeks. Plasma MCP-1 levels were measured at week 2 of repeated administration. Results are displayed using scatter plots with mean values for six animals in the normal and Nx groups and eight animals in the other groups. One-way ANOVA with Tukey's multiple comparisons test was used for comparisons between normal, $\mathrm{Nx}$, and vehicle groups, and two-tailed unpaired $t$ test was used for comparisons between vehicle and each drug group. ${ }^{\$} P<0.05$ vs. normal group, ${ }^{*} P<0.05$ vs. Nx group, ${ }^{\#} P<0.05$ vs. vehicle group. Correlations between $\log 10$-transformed plasma MCP-1 level and plasma creatinine level (B), urinary protein excretion (C), and scores of glomerulosclerosis (D) and interstitial fibrosis (E) at week 6 of repeated administration. Pearson correlation analysis was used for log10-transformed plasma MCP-1 vs. plasma creatinine and urinary protein excretion, and Spearman correlation analysis was used for $\log 10$-transformed plasma MCP-1 vs. scores of glomerulosclerosis and interstitial fibrosis.

were found between plasma MCP-1 levels and fibrotic lesions (glomerulosclerosis and tubulointerstitial fibrosis score) and also between plasma MCP-1 levels and renal function (urinary protein excretion and plasma creatinine). Thus, the renoprotective effects of AS3334034 are likely to be primarily due to inhibition of inflammation. To our knowledge, this investigation is the first to examine the renoprotective effects of a RIP2 inhibitor on progressive renal dysfunction in a CKD model. Given the known importance of renal inflammation as a common mechanism in the progression of not only nondiabetic but also diabetic kidney disease (Amdur et al., 2016), it is possible that RIP2 might also play a crucial role in the development and progression of diabetic nephropathy. Indeed, it has been reported that renal NOD2 expression is significantly elevated in patients with various inflammatory and proteinuric kidney diseases, including diabetic nephropathy, and that gene deletion of NOD2 attenuates renal inflammation and albuminuria in diabetic nephropathy mice (Du et al., 2013). 

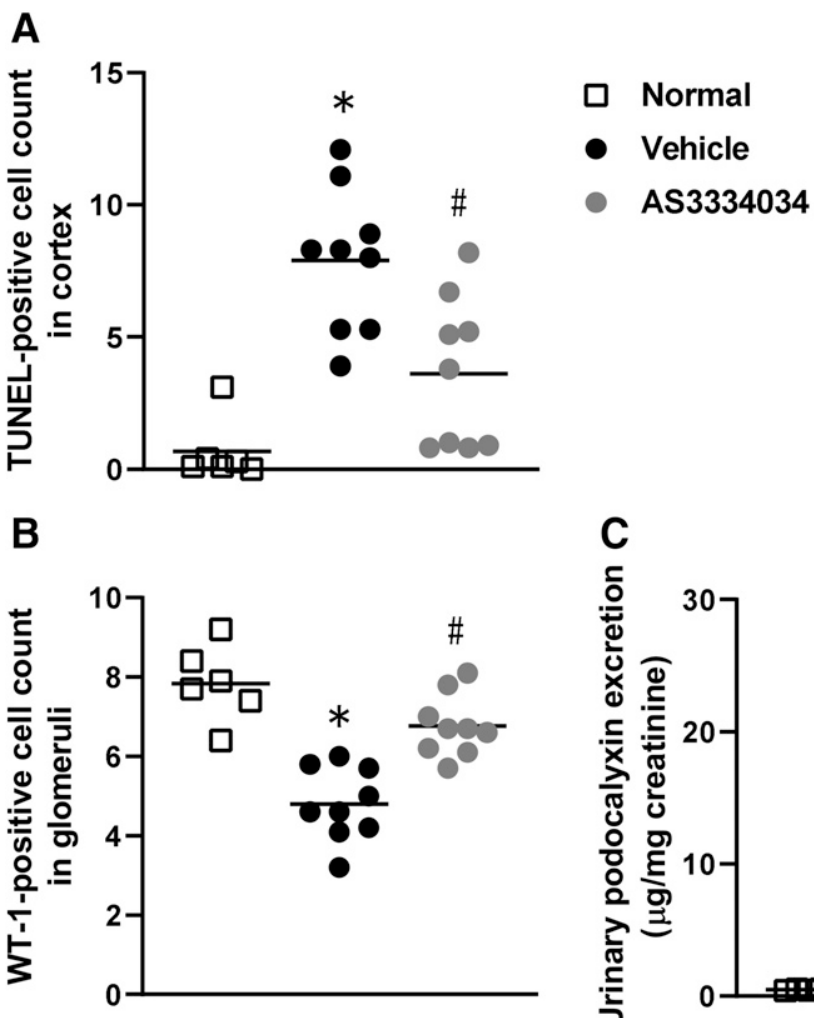

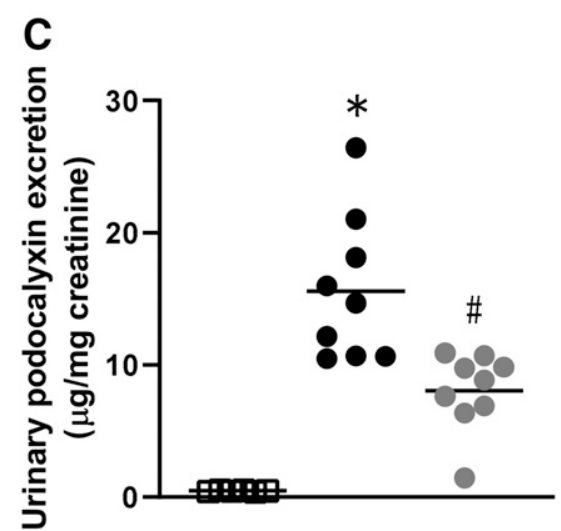

Fig. 8. Effects of 4 weeks' repeated administration of AS3334034 on renal apoptosis and glomerular podocyte injury in CKD rats. AS3334034 $(10 \mathrm{mg} / \mathrm{kg})$ was orally administered to $\mathrm{Nx}$ adriamycin-treated CKD rats for 4 weeks. Counts of TUNEL-positive cells (A) and WT-1-positive cells (B) and urinary podocalyxin excretion (C). Urinary podocalyxin excretions were measured at week 2 of repeated administration. Results are displayed using scatter plots with mean values for six animals in the normal group and nine animals in the other groups. Two-tailed unpaired $t$ test was used for comparisons between normal and vehicle group, and between vehicle and AS3334034 group. $* P<0.05$ vs. normal group, ${ }^{\#} P<0.05$ vs. vehicle group.
In addition, NOD signaling has been reported to be involved in the initiation and progression of various inflammation, such as endoplasmic reticulum stress-mediated inflammation (Keestra-Gounder et al., 2016), age-associated inflammation (Thevaranjan et al., 2018), and vascular inflammation including atherosclerosis (Kanno et al., 2015), which all are possible pathogenic factors underlying the development of CKD including diabetic nephropathy. Although further experiments using various models of CKD, including diabetic nephropathy models (Tahara and Takasu, 2018), are necessary to confirm these therapeutic effects, the RIP2 inhibitor AS3334034 may indeed be a promising drug for use in countering the progression of CKD.

The adriamycin-induced CKD model is known to exhibit prominent inflammation and podocyte damage, leading to glomerulosclerosis and tubulointerstitial fibrosis (Lee and Harris, 2011; Szalay et al., 2015) against which reninangiotensin-aldosterone system blocking agents, ACE inhibitors, and ARBs such as losartan showed a small or limited renoprotective effect (Nakhoul et al., 2005; Muñoz et al., 2011). Our results also showed losartan had a small or limited effect on renal dysfunction at $30 \mathrm{mg} / \mathrm{kg}$. In contrast, AS3334034 exhibited significant beneficial effects on renal function and injury in this CKD model. These results suggest that AS3334034 has renoprotective effects through anti-inflammatory effects, which differ from the effects of ACE inhibitors or ARBs through alteration of renal hemodynamics. On the other hand, losartan has shown potent renoprotective effects at $10-30 \mathrm{mg} / \mathrm{kg}$ in other CKD models, such as five-sixths nephrectomized CKD rats in our previous study and in another group's study (Vavrinec et al., 2011) and spontaneously hypertensive rat-background adriamycin-induced CKD rats (MihailovićStanojević et al., 2009). Although further investigation of the therapeutic combination effects of AS3334034 with these drugs in other CKD models will be needed, our results raise the expectation that AS3334034 may show an additive suppressive effect on the progression of $\mathrm{CKD}$ via different mechanisms.

In conclusion, the present results suggest that the RIP2 inhibitor AS3334034 suppresses the progression of chronic renal failure via an anti-inflammatory effect and that the NOD-RIP2 axis might play a crucial role in the pathogenesis of inflammatory kidney diseases. AS3334034 is expected to be potentially useful in the treatment of patients with CKD.

\section{Acknowledgments}

The authors thank Dr. Atsuo Tahara for helpful supports in consolidating data and writing manuscript and Drs. Yuichi Tomura, Masahiro Takeda, Akiyoshi Shimaya, Shin Naganuma, and Yutaka Inoki for their valuable comments and continuing encouragements for this project. The authors also thank Drs. Satoshi Kubo and Masaomi Terajima for establishing in vitro assays and Dr. Keitaro Kadono for measurements of AS3334034 in samples.

\section{Authorship Contributions}

Participated in research design: Wada, Kondo, Sakairi, Nagashima, Tokita.

Conducted experiments: Wada, Kondo, Sakairi, Nagashima, Tokita. Contributed new reagents or analytic tools: Tominaga.

Performed data analysis: Wada, Kondo, Sakairi, Tokita.

Wrote or contributed to the writing of the manuscript: Wada, Tomiyama, Ishikawa.

\section{References}

Amdur RL, Feldman HI, Gupta J, Yang W, Kanetsky P, Shlipak M, Rahman M, Lash JP, Townsend RR, Ojo A, et al.; CRIC Study Investigators (2016) Inflammation and progression of CKD: the CRIC study. Clin J Am Soc Nephrol 11:1546-1556.

Carrero JJ and Stenvinkel P (2009) Persistent inflammation as a catalyst for other risk factors in chronic kidney disease: a hypothesis proposal. Clin J Am Soc Nephrol 4 (Suppl 1):S49-S55. 
Dorsch M, Wang A, Cheng H, Lu C, Bielecki A, Charron K, Clauser K, Ren H, Polakiewicz RD, Parsons T, et al. (2006) Identification of a regulatory autophosphorylation site in the serine-threonine kinase RIP2. Cell Signal 18:2223-2229.

Du P, Fan B, Han H, Zhen J, Shang J, Wang X, Li X, Shi W, Tang W, Bao C, et al. (2013) NOD2 promotes renal injury by exacerbating inflammation and podocyte insulin resistance in diabetic nephropathy. Kidney Int 84:265-276.

Fried L, Solomon C, Shlipak M, Seliger S, Stehman-Breen C, Bleyer AJ, Chaves P, Furberg C, Kuller L, and Newman A (2004) Inflammatory and prothrombotic markers and the progression of renal disease in elderly individuals. J Am Soc Nephrol 15:3184-3191.

Ghosh SS, Krieg R, Massey HD, Sica DA, Fakhry I, Ghosh S, and Gehr TW (2012) Curcumin and enalapril ameliorate renal failure by antagonizing inflammation in 5/6 nephrectomized rats: role of phospholipase and cyclooxygenase. Am J Physiol Renal Physiol 302:F439-F454.

Gregg LP, Tio MC, Li X, Adams-Huet B, de Lemos JA, and Hedayati SS (2018) Association of monocyte chemoattractant protein-1 with death and atherosclerotic events in chronic kidney disease. Am J Nephrol 47:395-405.

Hato T and Dagher PC (2015) How the innate immune system senses trouble and causes trouble. Clin J Am Soc Nephrol 10:1459-1469.

Humphries F, Yang S, Wang B, and Moynagh PN (2015) RIP kinases: key decision makers in cell death and innate immunity. Cell Death Differ 22:225-236.

Inohara N, del Peso L, Koseki T, Chen S, and Núñez G (1998) RICK, a novel protein kinase containing a caspase recruitment domain, interacts with CLARP and regulates CD95-mediated apoptosis. J Biol Chem 273:12296-12300.

Jun JC, Cominelli F, and Abbott DW (2013) RIP2 activity in inflammatory disease and implications for novel therapeutics. J Leukoc Biol 94:927-932.

Kanno S, Nishio H, Tanaka T, Motomura Y, Murata K, Ihara K, Onimaru M, Yamasaki S, Kono H, Sueishi K, et al. (2015) Activation of an innate immune receptor, Nod1, accelerates atherogenesis in Apoe-/- mice. J Immunol 194:773-780.

Kazancioğlu R (2013) Risk factors for chronic kidney disease: an update. Kidney Int Suppl (2011) 3:368-371.

Keestra-Gounder AM, Byndloss MX, Seyffert N, Young BM, Chávez-Arroyo A, Tsai AY, Cevallos SA, Winter MG, Pham OH, Tiffany CR, et al. (2016) NOD1 and NOD2 signalling links ER stress with inflammation. Nature 532:394-397.

Kitagawa D, Yokota K, Gouda M, Narumi Y, Ohmoto H, Nishiwaki E, Akita K, and Kirii Y (2013) Activity-based kinase profiling of approved tyrosine kinase inhibitors. Genes Cells 18:110-122.

Lambers Heerspink HJ and de Zeeuw D (2013) Novel drugs and intervention strategies for the treatment of chronic kidney disease. Br J Clin Pharmacol 76:536-550.

Lebleu VS, Sugimoto H, Miller CA, Gattone VH II, and Kalluri R (2008) Lymphocytes are dispensable for glomerulonephritis but required for renal interstitial fibrosis in matrix defect-induced Alport renal disease. Lab Invest 88:284-292.

Lee BT, Ahmed FA, Hamm LL, Teran FJ, Chen CS, Liu Y, Shah K, Rifai N, Batuman V, Simon EE, et al. (2015) Association of C-reactive protein, tumor necrosis factoralpha, and interleukin-6 with chronic kidney disease. BMC Nephrol 16:77.

Lee VW and Harris DC (2011) Adriamycin nephropathy: a model of focal segmental glomerulosclerosis. Nephrology (Carlton) 16:30-38.

Lin SL, Chiang WC, Chen YM, Lai CF, Tsai TJ, and Hsieh BS (2005) The renoprotective potential of pentoxifylline in chronic kidney disease. J Chin Med Assoc 68:99-105.

López-Novoa JM, Martínez-Salgado C, Rodríguez-Peña AB, and López-Hernández FJ (2010) Common pathophysiological mechanisms of chronic kidney disease: therapeutic perspectives. Pharmacol Ther 128:61-81.

Lv W, Booz GW, Wang Y, Fan F, and Roman RJ (2018) Inflammation and renal fibrosis: recent developments on key signaling molecules as potential therapeutic targets. Eur J Pharmacol 820:65-76.

Magalhaes JG, Lee J, Geddes K, Rubino S, Philpott DJ, and Girardin SE (2011) Essential role of Rip2 in the modulation of innate and adaptive immunity triggered by Nod1 and Nod2 ligands. Eur J Immunol 41:1445-1455.

McCarthy JV, Ni J, and Dixit VM (1998) RIP2 is a novel NF-kappaB-activating and cell death-inducing kinase. J Biol Chem 273:16968-16975.

Meylan E and Tschopp J (2005) The RIP kinases: crucial integrators of cellular stress. Trends Biochem Sci 30:151-159.

Mihailović-Stanojević N, Jovović D, Miloradović Z, Grujić-Milanović J, Jerkić M, and Marković-Lipkovski J (2009) Reduced progression of adriamycin nephropathy in spontaneously hypertensive rats treated by losartan. Nephrol Dial Transplant 24:1142-1150.

Muñoz M, Rincón J, Pedreañez A, Viera N, Hernández-Fonseca JP, and Mosquera J (2011) Proinflammatory role of angiotensin II in a rat nephrosis model induced by adriamycin. J Renin Angiotensin Aldosterone Syst 12:404-412.

Nachbur U, Stafford CA, Bankovacki A, Zhan Y, Lindqvist LM, Fiil BK, Khakham Y, Ko HJ, Sandow JJ, Falk H, et al. (2015) A RIPK2 inhibitor delays NOD signalling events yet prevents inflammatory cytokine production. Nat Commun 6:6442.
Nakhoul F, Ramadan R, Khankin E, Yaccob A, Kositch Z, Lewin M, Assady S, and Abassi Z (2005) Glomerular abundance of nephrin and podocin in experimental nephrotic syndrome: different effects of antiproteinuric therapies. Am J Physiol Renal Physiol 289:F880-F890.

Pereira BJ, Shapiro L, King AJ, Falagas ME, Strom JA, and Dinarello CA (1994) Plasma levels of IL-1 beta, TNF alpha and their specific inhibitors in undialyzed chronic renal failure, CAPD and hemodialysis patients. Kidney Int 45:890-896.

Pozzi C, Andrulli S, Pani A, Scaini P, Roccatello D, Fogazzi G, Pecchini P, Rustichelli R, Finocchiaro P, Del Vecchio L, et al. (2013) IgA nephropathy with severe chronic renal failure: a randomized controlled trial of corticosteroids and azathioprine. $J$ Nephrol 26:86-93.

Salla M, Aguayo-Ortiz R, Danmaliki GI, Zare A, Said A, Moore J, Pandya V, Manaloor R, Fong S, Blankstein AR, et al. (2018) Identification and characterization of novel receptor-interacting serine/threonine-protein kinase 2 inhibitors using structural similarity analysis. J Pharmacol Exp Ther 365:354-367.

Saxena M and Yeretssian G (2014) NOD-like receptors: master regulators of inflammation and cancer. Front Immunol 5:327.

Sharma M, Doley P, and Das HJ (2018) Etiological profile of chronic kidney disease: a single-center retrospective hospital-based study. Saudi J Kidney Dis Transpl 29: 409-413.

Shigeoka AA, Kambo A, Mathison JC, King AJ, Hall WF, da Silva Correia J, Ulevitch RJ, and McKay DB (2010) Nod1 and nod2 are expressed in human and murine renal tubular epithelial cells and participate in renal ischemia reperfusion injury. $J$ Immunol 184:2297-2304.

Silverstein DM (2009) Inflammation in chronic kidney disease: role in the progression of renal and cardiovascular disease. Pediatr Nephrol 24:1445-1452.

Stinghen AE, Gonçalves SM, Martines EG, Nakao LS, Riella MC, Aita CA and Pecoits-Filho R (2009) Increased plasma and endothelial cell expression of chemokines and adhesion molecules in chronic kidney disease. Nephron Clin Pract 111:c117-c126.

Stroo I, Butter LM, Claessen N, Teske GJ, Rubino SJ, Girardin SE, Florquin S, and Leemans JC (2012) Phenotyping of Nod1/2 double deficient mice and characterization of Nod1/2 in systemic inflammation and associated renal disease. Biol Open 1:1239-1247.

Suliman ME and Stenvinkel P (2008) Contribution of inflammation to vascular disease in chronic kidney disease patients. Saudi J Kidney Dis Transpl 19: 329-345.

Szalay CI, Erdélyi K, Kökény G, Lajtár E, Godó M, Révész C, Kaucsár T, Kiss N, Sárközy M, Csont T, et al. (2015) Oxidative/nitrative stress and inflammation drive progression of doxorubicin-induced renal fibrosis in rats as revealed by comparing a normal and a fibrosis-resistant rat strain. PLoS One 10:e0127090.

Tahara A and Takasu T (2018) Prevention of progression of diabetic nephropathy by the SGLT2 inhibitor ipragliflozin in uninephrectomized type 2 diabetic mice. Eur J Pharmacol 830:68-75.

Tbahriti HF, Meknassi D, Moussaoui R, Messaoudi A, Zemour L, Kaddous A, Bouchenak M, and Mekki K (2013) Inflammatory status in chronic renal failure: the role of homocysteinemia and pro-inflammatory cytokines. World $J$ Nephrol 2: $31-37$.

Thevaranjan N, Puchta A, Schulz C, Naidoo A, Szamosi JC, Verschoor CP, Loukov D, Schenck LP, Jury J, Foley KP, et al. (2018) Age-associated microbial dysbiosis promotes intestinal permeability, systemic inflammation, and macrophage dysfunction. Cell Host Microbe 23:570.

Tigno-Aranjuez JT, Asara JM, and Abbott DW (2010) Inhibition of RIP2's tyrosine kinase activity limits NOD2-driven cytokine responses. Genes Dev 24:2666-2677. Vavrinec P, van Dokkum RP, Goris M, Buikema H, and Henning RH (2011) Losartan protects mesenteric arteries from ROS-associated decrease in myogenic constriction following 5/6 nephrectomy. J Renin Angiotensin Aldosterone Syst 12:184-194.

Wada Y, Abe M, Moritani H, Mitori H, Kondo M, Tanaka-Amino K, Eguchi M, Imasato A, Inoki Y, Kajiyama H, et al. (2016) Original Research: potential of urinary nephrin as a biomarker reflecting podocyte dysfunction in various kidney disease models. Exp Biol Med (Maywood) 241:1865-1876.

Yang Y, Yin C, Pandey A, Abbott D, Sassetti C, and Kelliher MA (2007) NOD2 pathway activation by MDP or Mycobacterium tuberculosis infection involves the stable polyubiquitination of Rip2. J Biol Chem 282:36223-36229.

Zhang D, Lin J, and Han J (2010) Receptor-interacting protein (RIP) kinase family. Cell Mol Immunol 7:243-249.

Address correspondence to: Yusuke Wada, Drug Discovery Research, Astellas Pharma Inc., 21 Miyukigaoka, Tsukuba, Ibaraki 305-8585, Japan. E-mail: yusuke.wada@astellas.com 